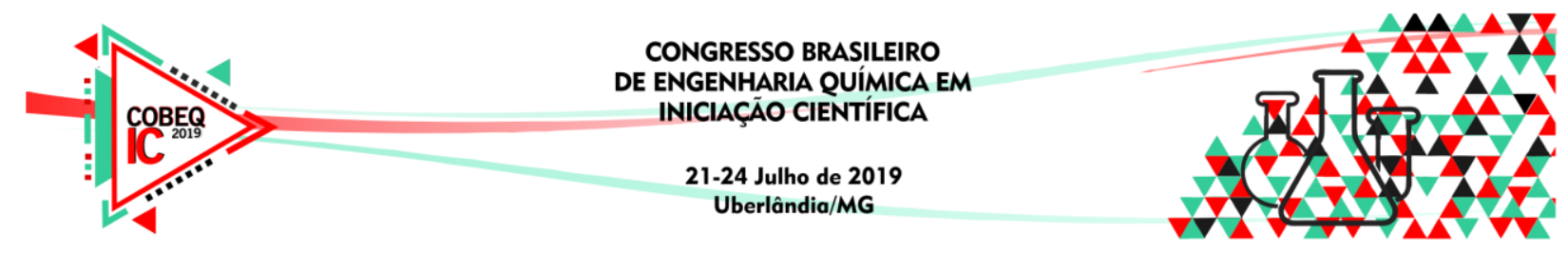

\title{
AVALIAÇÃO DA PRODUÇÃO DE METABÓLITOS PELA FOTOFERMENTAÇÃO E SISTEMAS HÍBRIDOS POR Rhodobacter capsulatus
}

\author{
W. R. CUNHA ${ }^{1}$, P. S. LAMOUNIER ${ }^{2}$, F. S. $\mathrm{PIO}^{2}$, V. L. CARDOSO ${ }^{2}$ e J. S. FERREIRA ${ }^{2}$ \\ ${ }^{1}$ Universidade Federal de Uberlândia, Instituto de Biotecnologia \\ ${ }^{2}$ Universidade Federal de Uberlândia, Faculdade de Engenharia Química \\ E-mail para contato: gmail.com
}

\begin{abstract}
RESUMO - A Rhodobacter capsulatus é uma bactéria fototrófica facultativa capaz de crescer numa ampla variedade de condições ambientais e através do processo de fotofermentação ela consegue transformar compostos orgânicos em hidrogênio, ácidos carboxílicos, álcoois e outros metabólitos. O presente trabalho apresenta um estudo da produção de metabólitos produzidos por Rhodobacter capsulatus, consumo de açúcares e aumento na concentração celular quando cultivada em meio sintético RCV e em efluente da fermentação escura (EFE), ambos com suplementação de $20 \mathrm{~g} / \mathrm{L}$ de melaço de soja. No ensaio 1 (meio RCV) o consumo de açúcares totais foi em torno de $32 \%$ e a produção de ácido acético e ácido propiônico atingiu $1,01 \mathrm{~g} / \mathrm{L}$ e $1,01 \mathrm{~g} / \mathrm{L}$, respectivamente. A concentração celular atingiu $1,11 \mathrm{~g} / \mathrm{L}$ e a razão $\mathrm{C} / \mathrm{N}$ apresentou um aumento de $36 \%$ ao final do experimento. No ensaio 2 (meio EFE) o consumo de açúcares foi de $63 \%$ e a produção de ácido acético atingiu 2,42 g/L. A concentração celular foi de 1,49 g/L e a razão $\mathrm{C} / \mathrm{N}$ se manteve durante o experimento. Com base nisso, afirma-se que a bactéria PNS $R$. capsulatus produziu ácidos acético e propiônico, sendo que a utilização do efluente da fermentação escura favoreceu a produção destes compostos, o crescimento celular e o consumo de açúcares em relação ao uso do meio sintético RCV.
\end{abstract}

\section{INTRODUÇÃO}

A Rhodobacter capsulatus é uma bactéria fototrófica facultativa capaz de crescer numa ampla variedade de condições ambientais (Gray et al. 1994). Essa bactéria metabolicamente versátil tem se mostrado extremamente valiosa em estudos de fotossíntese e fixação de nitrogênio, fornecendo conhecimentos extraordinários para esses processos com aplicações para outros organismos (Scolnik e Mars, 1987). As cepas de R. capsulatus é um tipo de bactéria púrpura não sulfurosa (PNS), que pode produzir hidrogênio, sob determinadas condições.

Nas últimas décadas, tem-se observado avanços significativos na produção de ácidos orgânicos pela transformação de biomassa via fermentação microbiana. Estes ácidos orgânicos podem ser usados diretamente, neste caso destaca-se o uso para a aplicação na indústria de alimentos, como também constituem moléculas chaves para a produção de outros compostos químicos. 


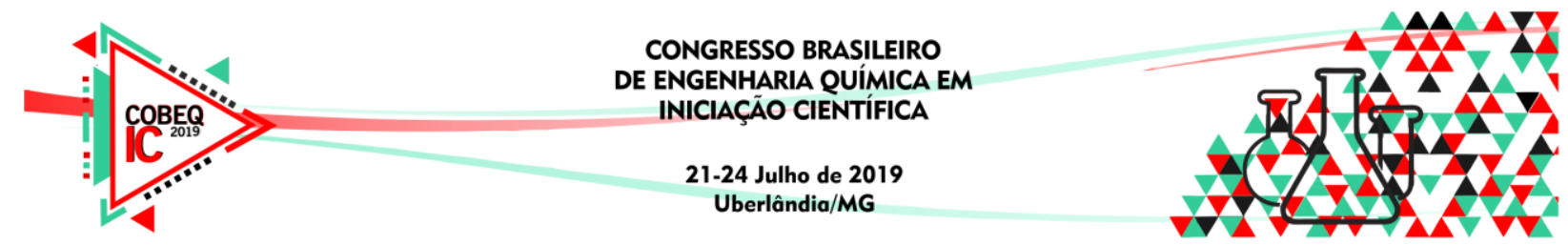

A maior aplicação do ácido lático e seus derivados é efetuada na indústria de alimentos, onde é utilizado com as funções de diminuição de pH; como agente antimicrobiano; adjuvante de sabor; solvente; estabilizador; umectante; emulsificador; plasticizante. De acordo com Sharpel (1985), o ácido butírico tem grandes aplicações nos gêneros alimentícios e de bebidas. Pode ser usado em sua forma pura na indústria de laticínios, ou na forma de ésteres como aditivo alimentar para aumentar o odor de frutas. $\mathrm{O}$ ácido propiônico tem muitos e variados usos, como agente antifúngico em alimentos e como ingrediente em termoplásticos, medicamentos antiartríticos, perfumes, sabores e solventes (Himmi et al. 2000).

Nesse contexto, o experimento realizado permitiu a quantificação do consumo de açúcares e a formação de ácidos orgânicos, presentes no meio RCV e no efluente da fermentação escura, utilizando melaço de soja como substrato.

\section{MATÉRIAL E MÉTODOS}

Para o seguinte trabalho foram utilizadas cepas de bactérias púrpuras não-sulfurosas (PNS), as Rhodobacter capsulatus (DSMZ - German Collection of Microorganisms and Cell Culture), no processo de fotofermentação. O cultivo foi realizado em meio basal RCV (Weaver et al., 1975) com o pH ajustado para 6,8, em frascos Duran de $500 \mathrm{~mL}$, no qual 70\% foi preenchido com meio de cultura e inóculo, os $30 \%$ restante de headspace foi saturado com gás argônio. Os frascos foram mantidos em uma câmara de germinação a $30 \pm 1{ }^{\circ} \mathrm{C}$, com iluminação de 2200 lux. No período de 10 a 12 dias, as cepas foram centrifugadas e o sedimentado era suspendido em um novo meio de cultura.

O meio fermentescível utilizado nos experimentos de fotofermentação foi o próprio meio basal RCV e o efluente proveniente da fermentação escura por consórcio microbiano em reator UASB, produzido em trabalho paralelo a esse. Para tornar o efluente adequado a fotofermentação. Primeiramente, ele foi centrifugação para a retirada de outras culturas de bactérias presente no meio. Posteriormente, realizou-se a suplementação do efluente com os componentes do meio basal RCV, com a exceção do ácido málico e do sulfato de amônio, com o pH ajustado para 6,8 para a fotofermentação. O substrato utilizado foi o melaço de soja em uma concentração de $20 \mathrm{~g} / \mathrm{L}$ nos dois meios fermentescíveis.

Os ensaios de fotofermentação foram realizados em reatores de $50 \mathrm{~mL}$ (frascos de penicilina), em duplicata. Foram conduzidos à temperatura de $32 \pm 1{ }^{\circ} \mathrm{C}$ e intensidade luminosa de 2200 lux. O volume reacional foi de $37,5 \mathrm{~mL}$, de meio a ser fermentado e inóculo. O headspace foi preenchido com gás argônio, caracterizando assim um ambiente anaeróbio.

Após a preparação dos reatores, eles foram tampados com septo de borracha butílica e lacrados com cápsulas de alumínio. Foram retiradas amostras iniciais do meio reacional, e a cada 2 dias eram coletadas novas amostras para análises, por um período de 10 dias.

A concentração de açúcares e de ácidos orgânicos foi medida por Cromatografia Líquida de Alta Eficiência, empregando-se um HPLC (Shimadzu modelo LC-20A proeminência, Supelcogel, coluna C-610H), em que os ácidos orgânicos foram detectados por luz ultravioleta e os açúcares foram detectados por índice de refração. 


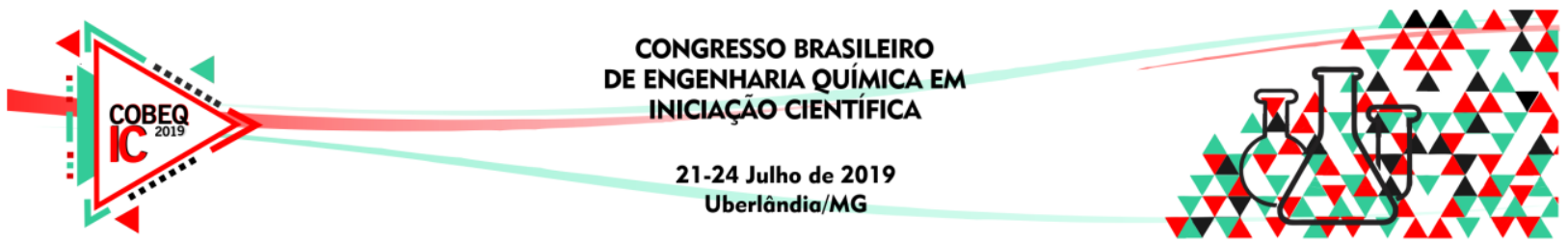

\section{RESULTADOS E DISCUSSÃO}

Tanto para o sistema de cultura pura em meio RCV (Ensaio 1) e em meio EFE (Ensaio 2), observa-se o consumo dos açúcares e também a degradação do tetrassacarídeo estaquiose e do trissacarídeo rafinose, o que justifica o aumento da concentração dos monossacarídeos, glicose e frutose, que, em seguida, são consumidos. A Figura 1 apresenta as concentrações de açúcares durante a fotofermentação.

Observa-se que a utilização da fonte de carbono é maior ao utilizar o meio EFE em relação ao meio RCV, sendo que o consumo de açúcares totais é em torno de 63 e 32\% respectivamente.

Figura 1 - Concentração de açúcares para cultura pura de $R$ capsulatus em meio (a) RCV e (b) EFE suplementado com $20 \mathrm{~g} / \mathrm{L}$ de melaço de soja.

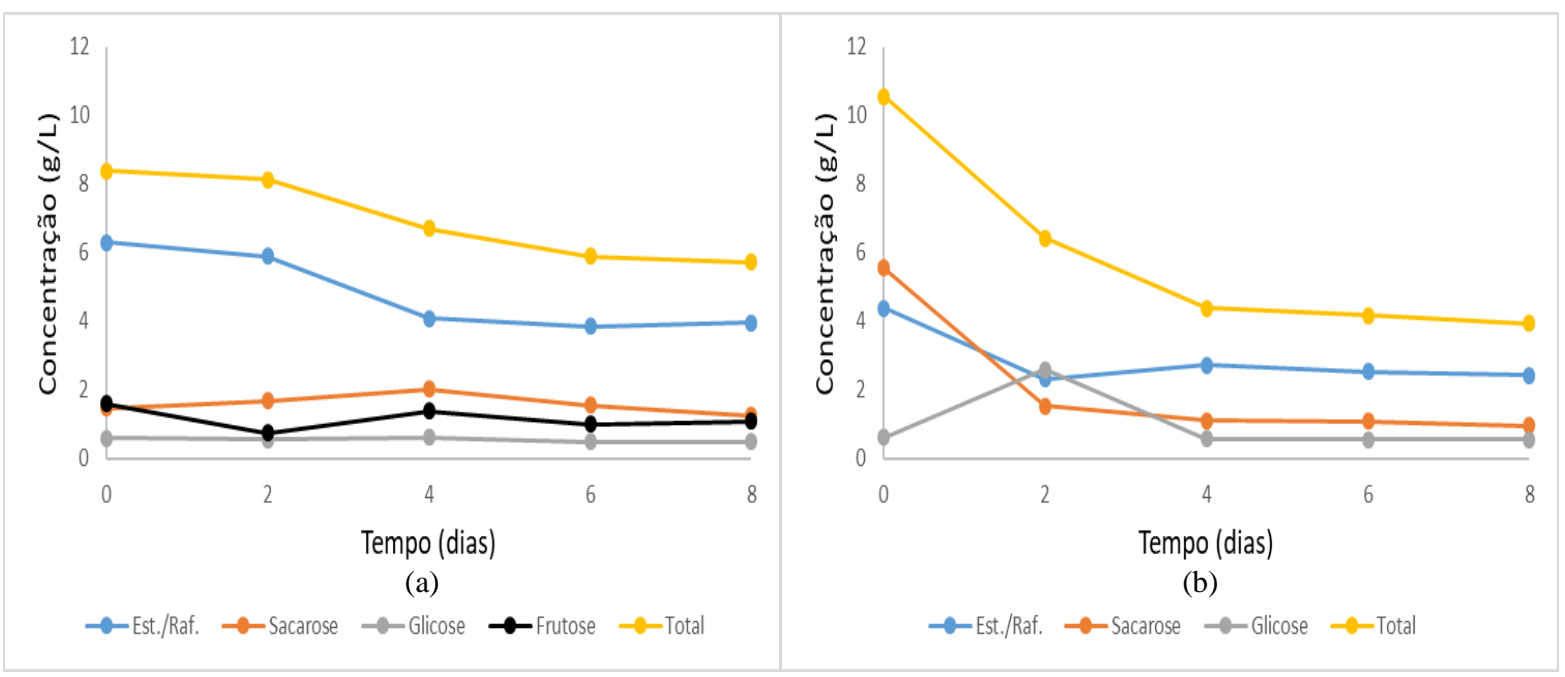

A partir dos resultados obtidos, Tabela 1, observa-se que a concentração inicial de ácidos orgânicos totais no cultivo em meio RCV foi de 5,13 g/L e em meio EFE foi de 8,53 g/L, já a concentração final de ácidos orgânicos totais foram de 5,11 g/L e 9,41 g/L, respectivamente. Predominam nestes meios a presença de ácido lático durante a fermentação até o oitavo dia, onde observa-se um consumo do ácido orgânico referido de 12,45\% no Ensaio 1 e 18,9\% no Ensaio 2.

Segundo Vieira et. al. (2016), o cultivo de Rhodopseudomonas palustris em meio EFE favorece a produção de ácidos orgânicos com suplementação de melaço de soja e apresenta melhores resultados para a produção de ácido acético e propiônico.

Semelhante ao comportamento da $R$. palustris, o cultivo da $R$ capsulatus durante a fermentação em meio RCV, houve maior produção de ácido acético e ácido propiônico, sendo que a concentração atingiu $1,01 \mathrm{~g} / \mathrm{L}$ e $1,01 \mathrm{~g} / \mathrm{L}$ respectivamente. Já para a fermentação em meio EFE, a maior produção foi de ácido acético atingindo $2,42 \mathrm{~g} / \mathrm{L}$. 


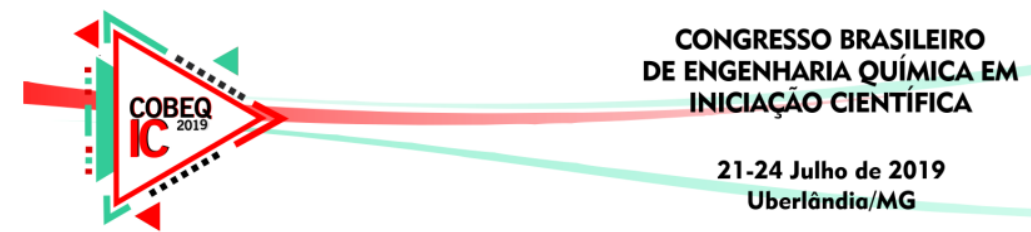

No oitavo dia de fotofermentação do Ensaio 1, a razão carbono/nitrato $(\mathrm{C} / \mathrm{N})$ apresentou um aumento de $36 \%$, o que pode ser indício de consumo de nitrogênio no meio, utilizado para o crescimento da biomassa. No entanto, para o Ensaio 2 a razão $\mathrm{C} / \mathrm{N}$ se manteve constante durante o experimento.

Tabela 1 - Concentração de ácidos orgânicos e razão C/N para cultura pura de $R$ capsulatus em meio RCV e meio EFE suplementado com 20g/L de melaço de soja .

\begin{tabular}{|c|c|c|c|c|c|c|c|}
\hline \multirow{2}{*}{ Meios } & \multirow{2}{*}{ Ácidos } & \multicolumn{5}{|c|}{ Concentrações nos dias $(\mathrm{g} / \mathrm{L})$} & \multirow{2}{*}{$\begin{array}{c}\text { Razão } \\
\text { C/N }\end{array}$} \\
\hline & & 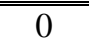 & 2 & $\overline{44}$ & $\overline{c 6}$ & 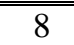 & \\
\hline \multirow{4}{*}{$\mathrm{RCV}$} & Lático & 4.45 & 0.88 & 3.91 & 3.47 & 3.90 & 20.05 \\
\hline & Acético & 0.68 & 0.21 & 1.04 & 0.76 & 1.01 & 9.10 \\
\hline & Propiônico & 0 & 0 & 0.17 & 0.12 & 0.20 & 14.25 \\
\hline & Butírico & 0 & 0 & 0 & 0 & 0 & 16.69 \\
\hline \multirow{4}{*}{ EFE } & Lático & 8.09 & 8.86 & 10.70 & 8.74 & 6.56 & 18.37 \\
\hline & Acético & 0 & 1.68 & 2.75 & 1.67 & 2.42 & 18.65 \\
\hline & Propiônico & 0.44 & 0.32 & 0.26 & 0.23 & 0.44 & 18.31 \\
\hline & Butírico & 0 & 0 & 0 & 0.10 & 0 & 16.80 \\
\hline
\end{tabular}

Observa-se, Tabela 2, que para o meio RCV a concentração celular final foi de $1,11 \mathrm{~g} / \mathrm{L}$, um aumento de $11 \%$, já para o meio EFE o aumento na concentração celular ao final de 8 dias foi de aproximadamente $50 \%$, em torno de $1,49 \mathrm{~g} / \mathrm{L}$.

Tabela 2 - Concentração celular de $R$ capsulatus em meio RCV e EFE suplementado com $20 \mathrm{~g} / \mathrm{L}$ de melaço de soja.

\begin{tabular}{|c|c||c|c|}
\hline \multicolumn{2}{|c||}{ Meio RCV } & \multicolumn{2}{c|}{ Meio EFE } \\
\hline \hline $\begin{array}{c}\text { Tempo } \\
(\text { dias })\end{array}$ & $\begin{array}{c}\text { Concentração } \\
(\mathrm{g} / \mathrm{L})\end{array}$ & $\begin{array}{c}\text { Tempo } \\
(\text { dias })\end{array}$ & $\begin{array}{c}\text { Concentração } \\
(\mathrm{g} / \mathrm{L})\end{array}$ \\
\hline \hline 0 & 1,00 & 0 & 1,00 \\
\hline 2 & 1,10 & 2 & 1,31 \\
\hline 4 & 1,13 & 4 & 1,27 \\
\hline 6 & 1,12 & 6 & 1,34 \\
\hline 8 & 1,11 & 8 & 1,49 \\
\hline
\end{tabular}

O ensaio de fotofermentação em meio EFE apresenta bons resultados na produção de ácidos orgânicos, principalmente o ácido acético, porém não altera significativamente a quantidade de ácido butírico e ácido propiônico. Mostra também melhoria no consumo de açúcares totais, maior aproveitamento de um resíduo agroindustrial (melaço de soja) e consequentemente aumento da concentração celular durante 8 dias.

\section{CONCLUSÃO}

Este estudo indica que a $R$ capsulatus cultivada em diferentes meios sofre alteração no crescimento celular, na produção de ácidos orgânicos e na capacidade de assimilar açúcares distintos. Conclui-se que o meio com efluente oriundo da fermentação escura de um consórcio microbiano, adaptado para as bactérias purpuras não sulforosas favorece a produção 


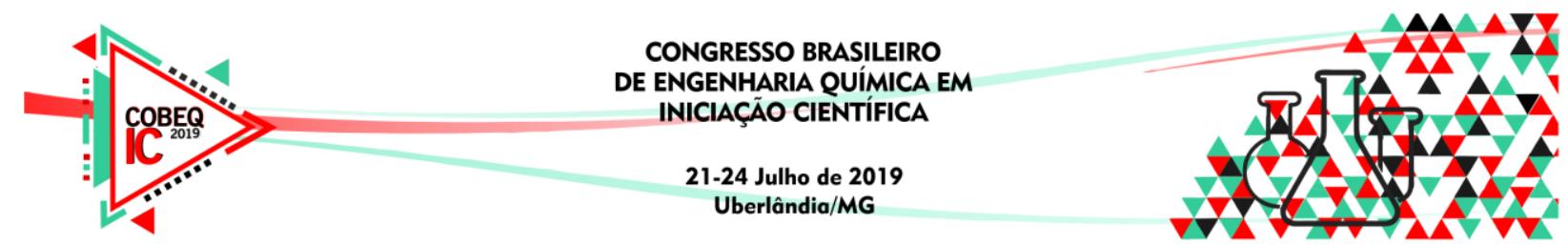

de ácidos orgânicos, o consumo de açúcares totais (63\%), o maior aproveitamento do melaço de soja e o aumento da concentração celular (50\%).

\section{AGRADECIMENTOS}

Os autores agradecem ao CNPq, CAPES, FAPEMIG, FAU e Vale S.A. pelo apoio e incentivo à pesquisa.

\section{REFERÊNCIAS}

GRAY, K. A., GROOMS, M., MYLLYKALLIO, H., MOOMAW, C., SLAUGHTER, C., \& DALDAL, F. Rhodobacter capsulatus contains a novel cb-type cytochrome c oxidase without a CuA center. Biochemistry, 33(10), 1994.

HIMMI, E. H., BORIES, A., BOUSSAID, A., \& HASSANI, L. Propionic acid fermentation of glycerol and glucose by Propionibacterium acidipropionici and Propionibacterium freudenreichii ssp. shermanii. Applied Microbiology and Biotechnology, 53(4), 435440, 2000.

SCOLNIK, P.A., MARS Genetic research th photosynthetic bacteria. Annu Rev Microbiol 41, 703-726, 1987.

SHARPEL, F.H.J. Microbial flavours and fragrances. In: Comprehensive Biotechnology (Blanch HW, Drew S and Wang DIC, eds), pp 965-979, Pergamon Press, Oxford, UK, 1985.

VIEIRA, L. M., MACHADO, R. G., BATISTA, F. R. X., CARDOSO, V. L., FERREIRA, J. S. Avaliação da produção de ácidos orgânicos por Rhodopseudomonas palustres utilizando meio sintético e efluente da fermentação escura. XXI Jornada em Engenharia Química. 209-213, 2016.

WEAVER, P. F.; WALL, J. D.; GEST, H. Characterization of Rhodopseudomonas capsulate. Archives of Microbiology, v. 105, p. 207-216, 1975. 